\title{
How Journalists Engage in Branding on Twitter: Individual, Organizational, and Institutional Levels
}

\begin{abstract}
In a social media age, branding is an increasingly visible aspect of identity construction online. For media professionals generally and journalists especially, branding on spaces such as Twitter reveals the complicated set of forces confronting such public-facing actors as they navigate tensions between personal disclosure for authenticity and professional decorum for credibility, and between establishing one's own distinctiveness and promoting one's employer or other stakeholders. While studies have begun to reveal what journalists say about branding, they have yet to provide a broad profile of what they $d o$. This study takes up that challenge through a content analysis of the Twitter profiles and tweets of a representative sample of 384 U.S. journalists. We focus on the extent of branding practices; the levels at which such branding occurs, whether to promote one's self (individual), one's news organization (organizational), or the journalism profession at large (institutional); and how other social media practices may be related to forms of journalistic branding. Results suggest that branding is now widely common among journalists on Twitter; that branding occurs at all three levels but primarily at the individual and organizational levels, with organizational branding taking priority; and that time on Twitter is connected with more personal information being shared.
\end{abstract}

Keywords: Branding; Brand Enactment; Identity; Journalistic Branding; Journalistic Roles; Social Media

Word Count:

\section{Authors}

[Corresponding Author]

Logan Molyneux

Temple University

2020 N. $13^{\text {th }}$ Street

Philadelphia, PA 19122

215-204-3092

logan@temple.edu

Twitter: @loganex

orcid.org/0000-0001-7382-3065

Logan Molyneux is an assistant professor of journalism at Temple University. His research focuses on digital media and mobile technology, specifically as they relate to journalistic practices and products. 
Avery Holton

University of Utah

avery.holton@utah.edu

Twitter: @averyholton

orcid.org/0000-0001-7498-0599

Avery Holton is an assistant professor of communication at the University of Utah. His research focuses on digital and social media, journalism, and health and disabilities communication.

Seth C. Lewis

University of Oregon

sclewis@uoregon.edu

Twitter: @SethCLewis

orcid.org/0000-0001-7498-0599

Seth C. Lewis is the inaugural Shirley Papé Chair in Electronic Media at the University of

Oregon. His research explores the social implications of media technologies for the dynamics of media work and innovation, particularly in the case of journalism and its digital transformation. 


\section{How Journalists Engage in Branding on Twitter: Individual, Organizational, and Institutional Levels}

\section{Introduction}

A defining feature of the social media age is impression management, or branding by another name (Marwick, 2013). Branding seeks to promote and differentiate a person or product for commercial purposes. By design, social media platforms allow and encourage users to cultivate an often public-facing persona, one organized around profile photos, status updates, and short but carefully crafted biographical statements, among other things. These social constructions of the self, while in some cases based on little more than 140-character tweets (Papacharissi, 2012), are complicated by the multiple potential audiences for any given post, as contexts of work, family, and friends co-exist and collide in many social media spaces (Marwick \& boyd, 2011). Meeting the expectations of various audiences in such an environment may be particularly challenging for media professionals, who are expected to blend the personal and the professional in the way they present themselves and their work on social media platforms. Indeed, for journalists especially, there is a growing expectation-whether felt personally, shared collectively, or even required organizationally - that they participate on social media, both to complement their reporting with behind-the-scenes transparency and personality and to extend the reach of their professional work and that of their colleagues. While seemingly pedestrian, these everyday engagements on social media reflect a broader turn toward branding. Thus, to study journalistic branding on social media is to reveal something about the tangle of forces shaping the social construction of identity online.

Perhaps nowhere is this more evident than in the complicated arrangement facing journalists on social media, as they seek new audiences, engage with sources, try to verify 
information, and deal with critics (Hermida, 2014). In one sense, journalists use social media to reach audiences directly and promote their own coverage, especially if they work a specific beat (Hedman, 2016; Lee, 2015; Olausson, 2016). However, they also are asked to promote their news organizations (Molyneux \& Holton, 2015), and they may see their work as contributing to a larger public service, giving people the information they need to be self-governing and thereby supporting the broader mission of journalism as an institution (Kovach \& Rosenstiel, 2007). Thus, when journalists engage in branding on social media, it often reflects a combination of emerging practices, with varying motivations, aims, and constituencies. Scholars examining tensions between professional and personal identities have called for analyses of journalistic branding that take into consideration organizational and institutional branding that may be increasingly present in journalists' social media feeds - that is, how journalists are enrolled in promoting themselves, their employers, and/or the larger "brand" of journalism and its normative value in society (Hedman \& Djerf-Pierre, 2013; Hermida, 2013; Siegert, Gertha, \& Rademachera, 2011).

This study takes up that challenge through a content analysis of the Twitter profiles and tweets of a sample of 384 journalists chosen at random from Cision, a large-scale database of journalists in the United States. In examining the profiles and tweets of these journalists, this study seeks to (1) develop a better understanding of journalistic branding by focusing on the extent of branding practices that journalists employ, while (2) also considering the levels at which such branding may occur (i.e., at individual, organizational, and institutional levels) and (3) what other social media practices may be related. Whereas extant research on journalistic branding has relied heavily on self-reports via surveys and interviews (Sacco \& Bossio, 2016), this study goes a step further, moving beyond what journalists say about branding to examine 
what they actually do (and how), placed in the context of Twitter, the most publicly used social media platform by U.S. journalists.

\section{LITERATURE REVIEW}

\section{Identity and Branding}

Based on the viewpoint that one's identity is a social construction (Goffman, 1959;

Erikson, 1968), all social interactions, including those on social media (Papacharissi, 2012), may be said to play some part in the development, maintenance or manifestation of an individual's identity. While social media provide platforms for the creation of identity, they also encourage impression management, which, as Marwick and boyd (2011, p. 126) show, is anything but simple: Because social media collapse social contexts among different types of audiences (e.g., family members, bosses, acquaintances), users trying to develop a following on Twitter may feel compelled to "continually monitor and meet the expectations of their followers." Navigating these channels forces individuals to constantly reimagine and redefine themselves through a limited number of characters and filtered photos that in many ways showcase the identity one wants be known by rather than the one that that is actually enacted (cf. Turkle, 2012). Most of these interactions may be relatively brief or inconsequential (especially on social media), but their total effect is one that contributes to shaping an individual's identity.

Some portion of these interactions, specifically those with a commercial orientation or motivation, may be considered forms of branding. In essence, branding is the work of differentiating a commercial entity (whether person, company or product) from competitors in the market and simultaneously making claims about that person, company or product (Murphy, 1987). Branding is not accomplished all at once; rather, its activities are frequently part of an 
organized campaign to establish a relationship with consumers and seek their loyalty, often via mass media (Coomber, 2002). A target audience is frequently identified, and messages are crafted to encourage an economic and emotional attachment to the object being branded (Allen \& Meyer, 1990; Nitins \& Burgess, 2014; Williams, 2012). These messages often reach beyond the object itself, relating the product to others offered by the same company (as in insurance bundles) or relating the product to competitors to assert an advantage. Thus, identity formation and maintenance has intrinsic psychological and emotional motivations because it pursues questions fundamental to the human experience (Who am I? Where do I fit in?). Branding, on the other hand, hopes to influence some future transaction by establishing a commercial entity (whether individual, organizational or institutional) as a known quantity and seeking to encourage loyalty among current and potential customers. Institutional branding may be less directly concerned with making money, but still seeks to establish the value of a product —in journalism's case, the news and the professionals who produce it.

For all professionals using social media as a branding tool, it can be difficult to navigate questions of how and when to mix personal information with professional branding appeals. People have long shown stubborn resistance to advertising and might be turned off by an entirely commercial social media presence. At the other extreme, an entirely personal social media account does little to serve one's professional goals. Somewhere there is an ideal mix of personal, relatable socializing that invites in other users and makes them more comfortable when encountering professional, promotional bids for attention and loyalty. This study looks for evidence of this mix, but focuses primarily on professional identity development in branding.

Journalists working at news organizations are a unique case in professional branding because they produce media content under their own names while also being employed by a 
larger brand and contributing to an even larger dialogue on current events. Other professionals for whom personal branding is important (speakers, entrepreneurs, real estate agents, and so on) are analogous to journalistic freelancers, working primarily for themselves or on commission. It's unlikely that these self-employed professionals would work to develop brands other than their own, whereas journalists working full-time for news organizations have acknowledged being encouraged by their employers to contribute to organizational branding and see themselves as part of a larger information economy that also warrants promotion (Holton \& Molyneux, 2015). Journalists' branding efforts promote journalism at varying organizational and structural levels, ranging from single works of journalism they produce to journalism's role as the Fourth Estate. Thus, in the case of journalists, the split between personal and professional is further complicated because professional branding work can be directed at developing individual, organizational, or institutional brands (see Figure 1).

Figure 1. Aspects of personal and professional identity among employed journalists.

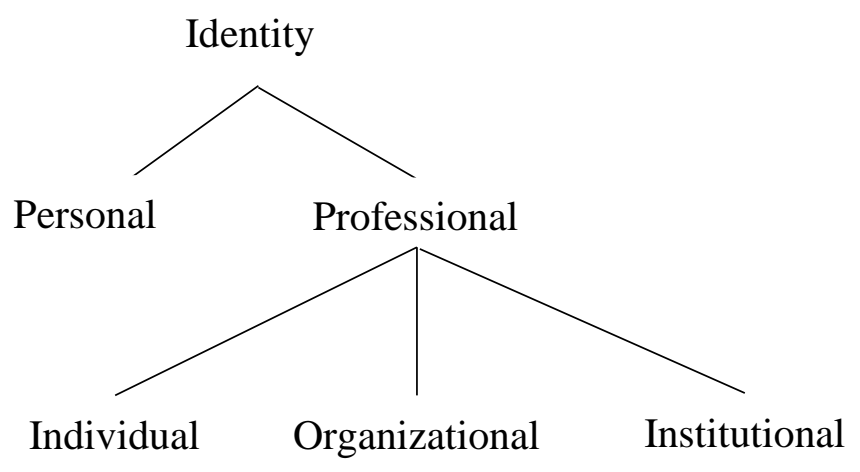

\section{Levels of Journalistic Branding: Individual, Organizational, Institutional}

"According to the gospel of the online age," a recent Columbia Journalism Review piece began, "personal branding is key to building a career in journalism." Highlighting a particularly 
visible form of branding for many journalists, the article continued: "Of all the tools journalists have at their disposal in their hunt for digital glory, the Twitter bio reigns high. But with only 160 characters available, it's not easy to strike that magical mix of informative, funny, and engaging" (Bech Sillesen, 2015). That the Columbia Journalism Review felt the need to ask "media marketing experts" to "evaluate the digital brands of some of the [news] industry's leading figures" raises the question: How did it get to be this way for journalists, and what are they doing to brand themselves online, particularly via Twitter?

Consider the present environment for media professionals. At a time when global publics are increasingly engaged in networked communication—-some 3.5 billion internet users, altogether contributing more than 400 million tweets per day, viewing 7.4 million YouTube videos every minute, and posting to Instagram 3.2 million times every hour (Internet Live Stats, 2016) - those who create and disseminate news and information are being compelled to adapt to the rhythms of social spaces online. Where once these creators, many of them journalists, controlled the flow of public communication, they now feel compelled to engage with audiences as never before (Lewis, 2012). The incorporation of Twitter and other social media into journalism has in many ways shifted the balance between journalists and their audiences (BelairGagnon, 2015), opening up opportunities for the public to contribute to the news process through content and contextualized contributions while facilitating more personalized forms of engagement that some of the public has come to expect (Canter, 2015; Hermida, 2014).

Social media also have challenged journalists to be more transparent in their work, more interactive with users, and more open to blending their professional and personal lives in the public sphere (Hedman, 2016; Lee, 2015; Olausson, 2016). This trend toward transparency sees journalists allowing audiences to observe professional (and occasionally personal) activities in an 
effort to appear more authentic and trustworthy (Hellmueller et al., 2012; Phillips, 2010; Revers, 2014). Such efforts at transparency share similar motives and forms with branding appeals.

Finally, journalists' adoption of social media has led to reconsideration of professional roles and norms. Responding to calls from their audiences, journalists have recognized the value of including opinion, humor, and personal information alongside their newswork (Bruns, 2012; Lee, 2015; Holton \& Lewis, 2011; Molyneux, 2015). These and other recent studies have illuminated several key deviations from the collective norms around which traditional journalism has long been organized. Such deviations include: (1) transparency through the inclusion of personal information and information about the journalism process, in a bid for authenticity; (2) more open gates to information as well as peer-to-peer connectivity through those gates, as opposed to limited audience feedback and engagement; (3) the expression of humor and opinion, in contrast to strict neutrality; (4) more connectivity with news consumers through the reposting of content on social media, versus simply broadcasting information; and (5) individual and organizational branding to promote the distribution of news content, rather than assuming a captive audience waiting to receive information.

As CNN senior media correspondent Brian Stelter put it: For journalists, "the lines between the personal and professional bleed in social media" (in Usher, 2014, p. 201). In such an environment for journalists, tensions have arisen between institutionally and organizationally policed boundaries of journalism (Carlson \& Lewis, 2015; Coddington, 2012), on the one hand, and individual decisions regarding how to adhere to or rebuke them, on the other (Sacco \& Bossio, 2016; Lee, 2015). Sacco and Bossio (2016) note that recent research has demonstrated how journalists are wrestling with competing messages of professionalism from their organizations and their audiences, and find themselves rethinking the boundaries between private 
and public as well as between their professional and personal identities. Journalists are developing brands that are driven by and reflective of organizational and institutional norms as much as they are connected to the individual journalists themselves (Friedman, 2015; Hedman, 2016; Molyneux \& Holton, 2015). They now recognize the need to create individual identities that illustrate their expertise while also giving a nod to the organizations that employ them and the institution of journalism that unifies them around an occupational sense of purpose (Canter, 2015; Hedman, 2016; Knight \& Cook, 2013).

Broadly, levels of influence such as these have been conceived as part of a hierarchy of influences that affect news media content (Shoemaker \& Reese, 2014). Three levels specifically—individual, organizational, and institutional — have emerged in previous research as the most relevant targets of branding activity among journalists (Holton \& Molyneux, 2015; Sacco \& Bossio, 2016). The individual level focuses on the individual journalist and his or her own identity. That identity may be manifest in personal and professional ways, both contributing to how the individual hopes to be perceived by others. The organizational level refers to the news organization represented by the journalist. Branding activity at this level seeks to promote the reputation and credibility of the entire news organization and the journalist's co-workers there. Finally, the institutional level deals with journalism as a profession (Waisbord, 2013), a recognizable collection of organizations and individuals that together make up the press. Journalists have been known to police the boundaries of the profession in order to assert their relevance and authority (Carlson \& Lewis, 2015; Coddington, 2012).

\section{Research questions}

Journalistic branding is thus a product of several pressures that journalists, their organizations, and their occupation are facing. As such, branding is manifest in appeals for 
attention at individual, organizational, and institutional levels. So far, work in the area of journalistic branding has involved self-reports via interviews or surveys (Sacco \& Bossio, 2016), with some scholars beginning to conduct content analysis (Hanusch \& Bruns, 2016). Studies have also focused on small groups of "top" journalists on Twitter (Brems et al., 2016) or those working in select media or on specific beats (Molyneux \& Holton, 2015). In this and other areas of study, scholars are moving beyond what journalists say about their work to study what they actually do in journalistic practice (Tandoc, Hellmueller, \& Vos, 2013; Mellado \& Lagos, 2014). This study builds on earlier findings by measuring what a broad cross-section of journalists actually do on social media, focusing on Twitter profiles and tweets. This study proposes three research questions that consider Twitter branding activity at three levels: individual, organizational, and institutional. Social media practices that may be occurring alongside branding are also considered.

RQ1a: To what extent do journalists engage in branding practices in their Twitter profiles?

$R Q 1 b:$ To what extent do journalists engage in branding practices in their tweets?

RQ2: How do journalists employ branding practices at individual, organizational, and institutional levels?

RQ3: What other social media practices are associated with branding among journalists?

\section{METHOD}

\section{Sample}

This study employs a content analysis of the Twitter profiles and tweets of a sample of U.S. journalists. The sample was drawn using a database maintained by the media listings 
service Cision, which has kept lists of media contacts in the U.S. for more than 75 years. Cision collects and verifies journalist contact information through web searches, association directories, e-mail, telephone, and mailings. The CisionPoint Media database was searched for those working at news organizations (including television stations and shows, radio stations and shows, newspapers and their bureaus, wire services, and news websites) with job descriptions containing any of the words "writer," "reporter," "columnist," "contributor," "correspondent," “anchor," and "journalist." This search purposefully excluded editors, producers, hosts, and so on, reasoning that these types of journalists do not typically have bylines and work more behind the scenes, therefore being less likely to have a public-facing social media presence.

This search yielded 25,599 individuals working for the following categories of media: newspapers, 58\%; television stations or shows, 19\%; news websites, $18 \%$; radio stations or shows, 5\%. Of these, 18,649 had Twitter accounts listed. This list was stratified according to the percentages in each media category in order to draw a random sample of 400 journalists (232 from newspapers, 75 from television, 73 from websites, and 20 from radio stations).

Some additional relevant information about each of these journalists was gathered from the CisionPoint database. In addition to listing which primary media type each journalist works for, the database contained circulation figures for newspaper journalists; Designated Market Area (DMA) rankings for television and radio broadcasters; and the number of unique monthly visitors for news websites. These numbers were spot checked for accuracy; no inconsistencies with publicly available data were found. These measures of audience size are on different scales (in two cases referring to individual readers/viewers and, in the case of DMA, a ranking of the potential audience's size), so these were converted to z-scores and combined into a single 
variable measuring audience size. This variable represents audience size relative to the other news outlets in the group rather than a raw number of readers or viewers.

A small number of the Twitter handles for these selected journalists were outdated. Internet searches were used to identify a current handle, if possible. Some profiles had been created but had never sent any tweets. One was not public. One was written entirely in Japanese. Excluding these left 384 journalists with working, public, English-language Twitter profiles. A custom software program scraped information from each of these journalists' Twitter profiles, including the profile bio, location (if any was listed), the date the user created the account, the number of followers, the number of tweets sent, and the user's five most recent tweets. This collection was run in March 2016 and resulted in 1,903 tweets.

A codebook was developed based on the literature covered earlier. It focuses on distinguishing among individual, organizational and institutional levels in both profiles and tweets (Sacco and Bossio 2016). The codebook incorporated elements from previous studies regarding the ways in which branding occurs, including through direct statements, links, retweets, and so on (Molyneux \& Holton, 2014; Molyneux, 2015; Hanusch \& Bruns, 2016; Brems et al., 2016). The codebook was divided into two main sections, focusing first on the journalists' profiles, then on their tweets, including branding elements and other social media practices within those tweets.

Journalist profiles. Each of the 384 profile bios was coded for whether the bio included: a reference the journalist's employer, a reference to another journalist, a reference to another news organization, a disclaimer (such as "retweets are not endorsements"), a mention of the journalist's beat or coverage area, and any personal information. Personal information is about the journalist himself or herself and does not deal with work or professional concerns. There was 
also a code for which of these elements appeared first. Finally, the journalists' Twitter handles were coded for whether they included a reference to the journalist's employer (such as @EliseLabottCNN).

Journalist tweets. Each of the collected tweets was coded for elements of branding, including a reference to the journalist himself or his own work (individual branding), a reference to the journalist's employer or a co-worker there (organizational branding), or a reference to another news organization or journalist (institutional branding). Tweets were coded for whether they included a link — and, if so, where that link pointed (to the journalist's own work, to that of a co-worker, that of another journalist outside their news organization, or elsewhere).

Tweets were also coded for whether they exhibited other popular social media practices among journalists found in previous research: a focus on public affairs; humor; opinion; and personal information (or lifecasting). In particular, these final three items (humor, opinion, and lifecasting) had been identified by previous studies as relevant practices among journalists on social media (Lasorsa, Lewis \& Holton, 2012; Lawrence et al., 2014). A focus on public affairs was interpreted to mean tweets dealing with news about politics, policy, government, economics, business and international affairs (not including sports, crime, entertainment and weather). Humor was coded when it appeared the journalist was attempting to use humor, including sarcasm, satire and jokes, within a tweet. Opinion was coded if the journalist expressed his or her own feelings about or evaluation of a news subject — not when retweeting someone else's opinion. Finally, personal information or lifecasting means tweets mentioning personal affairs or what the person is doing at that moment.

Two of the researchers served as coders. Intercoder reliability was established using a $10 \%$ sample of the profiles and tweets (38 profiles and 190 tweets from those 38 journalists). 
Overall raw agreement ranged from $94 \%$ to $100 \%$, and Krippendorf's alpha for all variables ranged from .84 to 1.00 , well within conventional levels of acceptable intercoder reliability (see Hayes \& Krippendorff, 2007).

\section{RESULTS}

Of the 384 profiles examined, $33(8.6 \%)$ had not posted a tweet in at least 6 months, meaning that most of the profiles had some level of recent activity. The profiles randomly selected for coding included Twitter celebrities such as CNN correspondent Christine Amanpour, with 1.7 million followers, and Fox Sports broadcaster Jay Onrait, with 556,000 followers. They also included four journalists with fewer than 20 followers each. Over the life of their accounts, the journalists had posted between 1 single tweet (in 2 cases) and 90,700 (in the case of Pete Prisco at CBS Sports). The number of tweets posted was divided by the length of time since the account had been created, giving a measure of tweets per year. These journalists published a median of 690 tweets per year, with outliers such as Prisco posting 13,550 per year.

\section{Journalist profiles}

The first research question (RQ1a) asked to what extent journalists engage in branding practices in their Twitter profiles. Table 1 displays frequencies for each form of branding measured. Most journalists (80\%) mentioned their employer in their Twitter profile, and about a third of journalists (29\%) included a reference to their employer in their Twitter handle itself (e.g. @ AshleyG_KVUE). A majority of profiles also mentioned their beat or coverage area (57\%), such as @BriannaEhley’s bio, which begins “Health care reporter at @Politico....” A majority also included personal information (53\%), such as mentioning where they were from or other personal tidbits. An example of this is the bio from Indianapolis Star reporter @DavidWoods007, which reads, in part, "Husband, father, Christ follower.” A smaller 
percentage mentioned another news organization (15\%), usually in the context of where they used to work (e.g. @ ddpan, a reporter for The Post and Courier in South Carolina, wrote “Formerly@TheInlander, @MotherJones”). Even fewer included a disclaimer (10\%), such as @etnh_niedzinski, a reporter for The Eagle-Tribune in New Hampshire, who wrote, "RT’s are not endorsements, opinions my own.” In all, 95\% of journalist profiles analyzed included at least one of these forms of branding, and $82 \%$ included two or more.

Bivariate correlations showed that some of these items frequently co-occur: Employer mention with beat or coverage area $(\mathrm{r}=.145, \mathrm{p}<.01)$, and a disclaimer with beat or coverage area $(r=.102, p<.05)$. If journalists included personal information, they were less likely to reference their employer in their Twitter handle $(\mathrm{r}=-.141, \mathrm{p}<.01)$. Table 1 also shows that, of the branding forms measured, employer affiliation was most often mentioned first in the profile (52\% of journalists used this form of branding first), followed by beat or coverage area (33\%).

Bivariate correlations also showed that journalists working at newspapers with larger circulations were more likely to include personal information in their bios $(r=.172, p<.05)$ and to mention their beat or coverage area $(r=.165, \mathrm{p}<.05)$. (No analogous relationships could be found using rankings of broadcast market areas or the number of unique visitors to a news website.) Also, the longer journalists had been on Twitter, the less likely they were to include a reference to their employer in their Twitter handle $(r=-.144, \mathrm{p}<.01)$.

Cross-tabulation tests revealed some differences in how journalists in different media (newspaper, news website, television, and radio) treated their Twitter profiles. TV journalists were more likely than other categories to include personal information (phi $=.161, \mathrm{p}<.05$ ). Those working at newspapers were more likely and those working at news websites were less likely to mention a beat or coverage area $(\mathrm{phi}=.389, \mathrm{p}<.001)$. Those working at news websites 
were more likely than other categories to include a reference to their employer in their Twitter handle $(\mathrm{phi}=.297, \mathrm{p}<.001)$. Finally, audience size was related in some ways to what journalists posted on their profiles. Journalists with relatively larger audiences were significantly more likely to mention their beat $(\mathrm{r}=.129, \mathrm{p}<.001)$, their employer $(\mathrm{r}=.104, \mathrm{p}<.001)$, and include a disclaimer $(\mathrm{r}=.066, \mathrm{p}<.01)$ in their Twitter bios.

\section{Journalist tweets}

The second research question (RQ1b) asked to what extent journalists engaged in branding practices in their tweets. Most of the tweets collected were original tweets in the author's own voice, as opposed to retweets $(27 \%)$ or quoted tweets $(5 \%)$. Even so, all these were coded for elements of branding because, as previous studies have found, elements of branding may also appear in retweets (Molyneux, 2014). Although 255 retweets (50\%) contained elements of branding, retweets were significantly less likely than normal tweets or quoted tweets to contain elements of branding (phi $=-.101, \mathrm{p}<.001)$.

Elements of branding appeared in $58 \%$ of all tweets, including branding at the individual, organizational or institutional level. These categories are distinct, but a single tweet may contain one or more of them together. The most common element of branding was a reference to the news organization for which the journalist works or a co-worker there (49\%), followed closely by references to the journalist's self or their own work (41\%). A smaller percentage of tweets contained a reference to another journalist or news organization $(21 \%)$. Most of the tweets that contained elements of branding also contained a link (90\%), and bivariate correlations confirm that, overall, branding and linking are strongly related $(\mathrm{r}=.551, \mathrm{p}<.001)$. Of the tweets containing both branding elements and a link, $40 \%$ of these links pointed to a journalist's own work and $39 \%$ pointed to a co-worker's work; $18 \%$ of these links pointed to another journalist 
working at a different news organization. Overall, only $13 \%$ of links pointed somewhere other than journalistic work. Finally, 33\% of the tweets containing branding elements focused on public affairs. Tweets containing elements of branding only infrequently contained elements of humor (2\%), opinion (3\%) and lifecasting (6\%).

Bivariate correlations revealed no relationships among branding practices and tenure on Twitter or number of followers. The more a person tweeted, the less likely any single tweet was to contain elements of branding $(r=-.088, \mathrm{p}<.05)$. As for audience size, journalists with larger audiences were more likely to send tweets containing elements of branding $(r=.069, \mathrm{p}<.01)$.

\section{Levels of branding}

RQ2 asked how journalists employ branding practices at individual, organizational, and institutional levels. The Twitter profile is, by definition, a form of branding, and the question is at which level this branding occurs. As indicated earlier, branding most frequently occurred at the organizational and individual levels. In this sample, $85 \%$ of journalists included a form of organizational branding in their Twitter profiles (either referencing the employer in the handle or mentioning who they work for in their bio-24\% did both). Individual branding appeared in $79 \%$ of profiles (either including personal information or a disclaimer-31\% did both). Institutional branding appeared in just $15 \%$ of profiles (mentioning another news organization or another journalist-less than $1 \%$ did both).

Journalists whose Twitter handles contain a reference to their employer were somewhat more likely to exhibit elements of branding in their tweets $(r=.091, p<.05)$, but this branding activity was more likely to happen at the organizational level $(\mathrm{r}=.167, \mathrm{p}<.001)$ and less likely to happen at the individual $(\mathrm{r}=-.139, \mathrm{p}<.001)$ and institutional levels $(\mathrm{r}=-.065, \mathrm{p}<.05)$. The variable counting how many tweets a journalist sent per year exhibited a similar pattern. The 
more tweets a journalist sent per year, the more likely they were to contain organizational branding $(\mathrm{r}=.123, \mathrm{p}<.001)$ and the less likely they were to contain individual branding $(\mathrm{r}=-$ $.156, \mathrm{p}<.001)$. Conversely, journalists whose bios contained personal information were more likely to exhibit tweets branded at the individual level $(\mathrm{r}=.065, \mathrm{p}<.05)$ and less likely to exhibit tweets branded at the organizational level $(r=-.141, \mathrm{p}<.001)$.

Bivariate correlations revealed negative associations among the three levels of branding measured here ( $\mathrm{r}$ between -.294 and $-.555, \mathrm{p}<.001$ ). Additionally, organizational branding was negatively associated with links $(r=-.072, \mathrm{p}<.05)$, whereas individual branding $(\mathrm{r}=.080, \mathrm{p}<$ $.01)$ and institutional branding $(\mathrm{r}=.198, \mathrm{p}<.001)$ were positively associated with links.

\section{Other social media practices}

The final research question, RQ3, asks what other social media practices are associated with branding among journalists. Small percentages of tweets exhibited humor (6\%), opinion $(6 \%)$, and personal information or lifecasting (7\%). Bivariate correlations show that these

practices are all negatively correlated with branding ( $\mathrm{r}$ between -.061 and $-.175, \mathrm{p}<.05$ or better) and linking ( $\mathrm{r}$ between -.127 and $-.177, \mathrm{p}<.001)$. On the other hand, tweets containing elements of branding also were associated with a focus on public affairs $(\mathrm{r}=.102, \mathrm{p}<.001)$. Public affairs tweets more frequently contained links $(r=.137, \mathrm{p}<.001)$ and were associated only with branding at the institutional level $(\mathrm{r}=.121, \mathrm{p}<.001)$ - that is, public affairs tweets were more likely to contain links to journalists at other news organizations.

\section{DISCUSSION}

In a social media age, branding is an increasingly salient aspect of identity construction online. For media professionals generally and journalists especially, branding on spaces such as 
Twitter offers a window into the complicated set of forces confronting such public-facing actors. These include tensions between disclosing personal information to be authentic or maintaining a professional presence to be authoritative, and tensions between developing one's individual distinctiveness at the expense of promoting one's employer or other stakeholders. While studies have begun to reveal what journalists say about branding, they have yet to provide a broad profile of how they enact branding. Implicitly, branding practices are evident in a broad array of research on digital journalism — from emerging efforts to develop mutually beneficial forms of 'reciprocal journalism' between journalists and communities (Lewis, Holton, \& Coddington, 2014), to journalistic negotiations of authority and verification amid the rise of user-generated content, as illustrated in the BBC's remaking of crisis reporting on social media (Belair-Gagnon, 2015). This study sought to go a step further in identifying more explicit forms of branding in Twitter profiles and tweets among a representative sample of U.S. journalists.

The results suggest that branding is now a common practice among journalists. In all, 95\% of journalists' Twitter profiles contained elements of branding measured in this study, and a majority of their tweets (58\%) also contained elements of branding. Furthermore, $87 \%$ of the links that journalists included in their tweets pointed to work done by a journalist—split roughly equally between themselves, their co-workers, and journalists at other news organizations. Thus, a substantial portion of U.S. journalists' Twitter activity is focused on promoting themselves, their companies, and journalism in general.

A cynical view of this finding might be that this branding activity is occurring at the expense of engaging the public in discourse around public affairs. While it's true that tweets containing branding elements are associated with a focus on public affairs, this likely is the result of overlapping interests - e.g., journalists who cover public affairs tweeting about their beat, or a 
prevalence of election news given the 2016 U.S. presidential campaigns - rather than a concerted effort to combine the two. Previous research (Hermida, Lewis, \& Zamith, 2014; Lawrence et al., 2014) has found that journalists on Twitter are an insular group, speaking mostly to one another via social media, and this study supports that conclusion. This may be viewed as a turn away from the audience, or a turn toward strengthening professional identity among like-minded colleagues. Indeed, given the level of hate and trolling that many public figures encounter on social media, perhaps it's not surprising that journalists appear to use social media more for broadcast-style content promotion and/or discussion among themselves and less for engaging audiences as potential collaborators and interlocutors (cf. Lewis et al. 2014).

Indeed, considering these findings from the perspective of journalists, it may be that they feel branding is their best shot at maintaining relevance and establishing authority, and that other uses of social media drain limited resources. Journalists' workloads have increased as staff sizes have dwindled, and new publishing platforms create additional spheres of responsibility. Many journalists feel that their jobs, even their industry as a whole, are in jeopardy, and thus may see branding activities as a way to retain and expand their audiences - thereby justifying themselves to bosses increasingly concerned with generating exposure across multiple platforms (Molyneux \& Holton, 2014). They may also be following regulations instituted by some news organizations that call for professional branding in journalists' Twitter bios as well as in their content. Moreover, just as isomorphic tendencies toward homogenization and mimicry are evident in the way organizations within institutional fields monitor and imitate one another (Boczkowski, 2010; Lowrey, 2011), individual journalists, too, may feel obligated to develop a social media presence to mirror those of many prominent journalists with large numbers of followers. These regulatory pressures, whether enacted organizationally or manifest personally, deserve further 
consideration. Whatever the reason, that branding is so common among journalists on Twitter suggests that it is seen as an acceptable, even obvious, practice among journalists of all stripes.

Perhaps a more intriguing finding is that branding is occurring primarily at the

organizational and individual levels, with organizational branding having a lead in some ways. A previous study found that journalists perceived a shift in emphasis from their employers: away from allowing anything and everything in the early days of Twitter, and toward an expectation that journalists should promote their employer and its news products (Holton \& Molyneux, 2015). This study reinforces this shift in emphasis, and suggests that it may be tipping the scales in favor of organizational branding. Longitudinal research in this area is needed to confirm this suspicion.

A relevant point in this line of thinking is that journalists in this sample who have been on Twitter longer were more likely to engage in individual branding rather than organizational branding. Several factors may be at play. As mentioned earlier, journalists who joined Twitter early on did so perhaps mostly for personal reasons, before employers began paying attention or became involved in establishing social media guidelines (cf. Canter, 2014). Those who joined later may have been prompted to do so by their employers, thereby approaching the platform with an organizational mind-set, as another aspect of one's job requirements. For those who joined for personal reasons, their Twitter experience is an intersection of personal and professional outreach, whereas it is more heavily organizational for those who joined, presumably, at the behest of their bosses. In both cases, however, tensions arise between individual and organizational interests, and these may prove difficult for journalists and their employers to navigate. 
A second factor might be that those with greater tenure on the platform have amassed a greater following, and therefore feel more comfortable being their own brand rather than relying on organizational cachet. As their following continues to grow, they may feel more at liberty to develop a personal relationship with their audience and focus branding activities at the individual level. This is further enhanced if, as is often the case, journalists move from company to company but maintain their own Twitter account and following. Transience in journalism jobs would tend to favor individual branding over organizational branding in the long run.

Branding at the individual level is a particularly thorny area, not least because it involves both personal and professional appeals. That is, speaking about one's personal life is a form of branding that serves to form and strengthen relationships with followers. This is distinct from a journalist's professional branding pursuits, which focus on his or her work. Both of these branding activities relate to the journalist as an individual rather than as part of an organization. The coding in this study noted cases of individual branding, but did not separate personal and professional elements except in the case of links. Links pointing to a journalist's own work are individual and professional, whereas links pointing to a selfie (or other personal information) focus on the individual at a personal level. These purely personal links were only a small portion of the overall number of links, suggesting that professional branding takes precedence over personal branding when it comes to links shared. In Twitter bios, a majority of journalists (57\%) included personal information, but only $14 \%$ of them mentioned it first. Whether this prioritizing of the professional over the personal has changed over time cannot be deduced from this study.

Another finding dealing with the personal side of branding is that television journalists were more likely than other kinds of journalists to engage in individual branding on their profiles. Hedman (2016) noted that channels or platforms play a significant role in influencing 
some forms of engagement on Twitter, such as branding. This finding speaks to research on parasocial interaction, which suggests that audiences can feel socially connected to a media figure on a personal basis (Giles, 2002). Television audiences, in this case, may feel a connection with a news anchor as an individual more so than with his or her television station, and so television journalists may be looking to capitalize on that connection in their Twitter branding activities.

This study focuses on a sample of U.S. journalists, but it may not represent branding activities in other cultures or languages around the globe. The U.S. media situation is distinct in terms of journalistic norms and consumer culture, so additional research is needed to understand branding practices as they exist elsewhere. This study also focuses on a snapshot of journalistic profiles and tweets in March 2016, and therefore cannot identify trends in branding practices beyond comparisons with previous studies. Additional studies, particularly longitudinal ones, are necessary to track how branding practices may be changing or evolving in response to pressures from the profession, audiences, competitors, technologies, economics, and so forth. At a broader level, the societal norms of social media engagement may also be driving how journalists view and engage branding on Twitter and similar platforms. This study is of branding on Twitter, and journalistic branding may be enacted differently on Facebook, Instagram, or other social media. Specifically, it's possible that visual journalists would have more of a presence on Instagram, and that distinctions between personal and professional may be even messier on Facebook given the deeper profile and varied means of interpersonal interaction. Finally, future research may consider combining interviews and content analysis (e.g., see Brems et al., 2016), asking journalists why they posted what they did to understand the thinking and motivations behind specific, observed branding practices. 
Overall, the findings here echo the notion that "personal branding is key to building a career in journalism" (Bech Sillesen, 2015), and correspond with emerging research on the role of branding in professional norms and practices (Hanusch \& Bruns, 2016; Hedman, 2015; Holton \& Molyneux, 2015; Molyneux \& Holton, 2015; Sacco \& Bossio, 2016). In the present study, the prevalence of branding among journalists in various media and with varying levels of experience on Twitter shows that, to a great degree, journalists are using social media to make appeals for attention and authority. Even at only 140 characters, journalistic branding as it is enacted on Twitter can have a meaningful impact in the social construction of journalists' personal and professional identities, the presentation of the news organizations they represent, and broader perceptions about the place and purpose of the institution of journalism. Ultimately, such efforts matter insofar as they influence audiences to develop similar impressions of journalists and their brands. 


\section{References}

Allen, N. J., \& Meyer, J. P. (1990). The measurement and antecedents of affective, continuance and normative commitment to the organization. Journal of Occupational Psychology 63(1): $1-18$.

Bech Sillesen, L. (2015). Analyzing journalists' Twitter bios. Columbia Journalism Review. Available at http://www.cjr.org/analysis/analyzing_journalists_twitter_bios.php

Belair-Gagnon, V. (2015). Social media at BBC news: The re-making of crisis reporting. London: Routledge.

Boczkowski, P. J. (2010). News at work: Imitation in an age of information abundance. Chicago: University of Chicago Press.

Brems, C., Temmerman, M., Graham, T., \& Broersma, M. (2016). Personal Branding on Twitter. Digital Journalism, published online before print. http://doi.org/10.1080/21670811.2016.1176534

Broersma, M., \& Graham, T. (2013). Twitter as a news source: How Dutch and British newspapers used tweets in their news coverage. Journalism Practice, 4(4), 446-464.

Bruns, A. (2012). Journalists and Twitter: How Australian news organisations adapt to a new medium. Media International Australia, 144(1), 97-107.

Canter, L. (2015). Personalised Tweeting: The Emerging Practices of Journalists on Twitter. Digital Journalism, 3(6), 888-907.

Carlson, M., \& Lewis, S. C. (Eds.) (2015). Boundaries of journalism: Professionalism, practices and participation. New York: Routledge.

Coddington, M. (2012). Defending a paradigm by patrolling a boundary two global newspapers' approach to WikiLeaks. Journalism \& Mass Communication Quarterly, 89(3), 377-396.

Coddington, M. (2014). Defending judgment and context in 'original reporting': Journalists' construction of newswork in a networked age. Journalism, 15(6), 678-695.

Coddington, M., Molyneux, L., \& Lawrence, R. G. (2014). Fact Checking the Campaign: How Political Reporters Use Twitter to Set the Record Straight (or Not). International Journal of Press/Politics, 19(4), 391-409. 
Coomber, S. (2002) Branding. Oxford: Capstone Publishing.

Djerf-Pierre, M., Ghersetti, M., \& Hedman, U. (2016, ahead of print). Appropriating social media: The changing uses of social media among journalists across time. Digital Journalism.

Erikson, E. H. (1968). Identity: Youth and crisis. New York: W. W. Norton.

Friedman, A. (2015). Me, Inc.: The paradoxical, pressure-filled quest to build a "personal brand." New Republic. Available at https://newrepublic.com/article/122910/my-paradoxicalquest-build-personal-brand

Giles, D. C. (2002). Parasocial interaction: A review of the literature and a model for future research. Media Psychology, 4(3), 279-305.

Goffman, E. (1959). The Presentation of Self in Everyday Life. New York: Doubleday.

Hanusch, F., \& Bruns, A. (2016, ahead of print). Journalistic Branding on Twitter: A representative study of Australian journalists' profile descriptions. Digital Journalism.

Hayes, A. F., \& Krippendorff, K. (2007). Answering the call for a standard reliability measure for coding data. Communication Methods and Measures, 1(1), 77-89.

Hedman, U. (2015). J-Tweeters: Pointing towards a new set of professional practices and norms in journalism. Digital Journalism, 3(2), 279-297.

Hedman, U. (2016). When Journalists Tweet: Disclosure, Participatory, and Personal Transparency. Social Media + Society, January-March, 1-13.

Hedman, U., \& Djerf-Pierre, M. (2013). The social journalist: Embracing the social media life or creating a new digital divide? Digital Journalism, 1(3), 368-385.

Hellmueller L., Vos, T. P., \& Poepsel, M. A. (2012). Shifting journalistic capital? Transparency and objectivity in the twenty-first century. Journalism Studies, 14(3), 287-304.

Hermida, A. (2014). Twitter as an ambient news network. In K. Weller, A. Bruns, J. Burgess, M. Mahrt \& C. Puschmann (Eds.), Twitter and Society (pp. 359-372). New York: Peter Lang.

Hermida, A. (2013). \#Journalism: Reconfiguring journalism research about Twitter, one tweet at a time. Digital Journalism, 1(3), 295-313. 
Hermida, A., Lewis, S. C., \& Zamith, R. (2014). Sourcing the Arab Spring: A case study of Andy Carvin's sources on Twitter during the Tunisian and Egyptian revolutions. Journal of Computer-Mediated Communication, 19(3), 479-499.

Holton, A., \& Lewis, S. C. (2011). Journalists, social media, and the use of humor on Twitter. The Electronic Journal of Communication / La Revue Electronic de Communication, 21(1-2).

Holton, A. E. \& Molyneux, L. (2015). Identity lost? The personal impact of brand journalism. Journalism (ahead of print), 1-16.

Internet Live Stats. (2016). Daily usage statistics. Available at http://www.internetlivestats.com/

Knight, M., \& Cook, C. (2013). Social media for journalists: Principles \& practice. London: Sage.

Kovach, B., \& Rosenstiel, T. (2007). The elements of journalism: What newspeople should know and the public should expect. Three Rivers Press (CA). Chicago

Lasorsa, D. L., Lewis, S. C., \& Holton, A. E. (2012). Normalizing Twitter: Journalism practice in an emerging communication space. Journalism Studies, 13(1), 19-36.

Lawrence, R. G., Molyneux, L., Coddington, M., \& Holton, A. (2014). Tweeting Conventions: Political journalists' use of Twitter to cover the 2012 presidential campaign. Journalism Studies, 15(6), 789-806.

Lee, A. M. (2015). Social media and speed-driven journalism: expectations and practices. International Journal on Media Management, 17(4), 217-239.

Lewis, S. C. (2012). The tension between professional control and open participation: Journalism and its boundaries. Information, Communication \& Society, 15(6), 836-866.

Lewis, S. C., Holton, A. E., \& Coddington, M. (2014). Reciprocal journalism: A concept of mutual exchange between journalists and audiences. Journalism Practice, 8(2), 229-241.

Lowrey, W. (2011). Institutionalism, news organizations and innovation. Journalism Studies, 12(1), 64-79. doi:10.1080/1461670X.2010.511954

Marwick, A. E. (2013). Status update: Celebrity, publicity, and branding in the social media age. New Haven: Yale University Press. 
Marwick, A. E., \& Boyd, D. (2011). I tweet honestly, I tweet passionately: Twitter users, context collapse, and the imagined audience. New Media \& Society, 13(1), 114-133.

Mellado, C., \& Lagos, C. (2014). Professional roles in news content: Analyzing journalistic performance in the Chilean national press. International Journal of Communication, 8, 20902112.

Mellado, C., \& Van Dalen, A. (2014). Between rhetoric and practice: Explaining the gap between role conception and performance in journalism. Journalism Studies, 15(6), 859-878.

Molyneux, L. (2015). What journalists retweet: Opinion, humor, and brand development on Twitter. Journalism, 16(7), 920-935.

Molyneux, L., \& Holton, A. E. (2015). Branding (health) journalism. Digital Journalism, 3(2), 225-242.

Mourão, R., Diehl, T., \& Vasudevan, K. (2015). I Love Big Bird. Digital Journalism, ahead of print, 1-18. http://doi.org/10.1080/21670811.2015.1006861

Murphy, J. M. (1987) Branding: A Key Marketing Tool. Princeton, NJ: McGraw-Hill Companies.

Nitins, T., \& Burgess, J. (2014). Twitter, brands, and user engagement. In K. Weller, A. Bruns, J. Burgess, et al. (Eds.), Twitter and Society. New York: Peter Lang, pp. 293-304.

Olausson, U. (2016). The reinvented journalist: The discursive construction of professional identity on Twitter. Digital Journalism, ahead of print, 1-22.

Papacharissi, Z. (2012). Without You, I'm Nothing: Performances of the Self on Twitter. International Journal of Communication, 6, 1989-2006.

Phillips, A. (2010) Transparency and the new ethics of journalism. Journalism Practice 4(3): 373-382.

Pew Research Center (2015) Newspapers: Fact Sheet. Available at http://www.journalism.org/2015/04/29/newspapers-fact-sheet/

Revers, M. (2014). The Twitterization of news making: Transparency and journalistic professionalism. Journal of Communication, 64(5), 806-826.

Sacco, V., \& Bossio, D. (2016, ahead of print). Don't tweet this! Digital Journalism. 
Shoemaker, P. J., and Reese, S.D. (2014). Mediating the message in the 21st century: A media sociology perspective. New York: Routledge.

Siegert, G., Gertha, M. A., \& Rademachera, P. (2011). Brand Identity-Driven Decision Making by Journalists and Media Managers - The MBAC Model as a Theoretical Framework. International Journal on Media Management, 13(1), 53-70.

Tandoc, E. C., Hellmueller, L., \& Vos, T. P. (2013). Mind the gap: Between journalistic role conception and role enactment. Journalism Practice, 7(5), 539-554.

Turkle, S. (2012). Alone together: Why we expect more from technology and less from each other. New York: Basic Books.

Usher, N. (2014). Making news at The New York Times. Ann Arbor: University of Michigan Press.

Waisbord, S. (2013). Reinventing professionalism: Journalism and news in global perspective. Cambridge: Polity.

Wiik, J. (2015). Internal boundaries: The stratification of the journalistic collective. In M. Carlson S. C. \& Lewis (Eds.), Boundaries of journalism: Professionalism, practices and participation (pp. 118-133). New York: Routledge.

Williams, J. (2012). The basics of branding. Entrepreneur. Available at: http://www.entrepreneur.com/article/77408 
Table 1. Frequency of branding elements in journalists' Twitter profiles

\begin{tabular}{lcc}
\hline $\begin{array}{l}\text { Branding element } \\
\text { mentioned in profile }\end{array}$ & Frequency $(\%)$ & $\begin{array}{c}\text { Percent of journalists } \\
\text { mentioning this item first in } \\
\text { the profile }(\%)\end{array}$ \\
\hline Employer affiliation & 80 & 52 \\
Beat or coverage area & 57 & 33 \\
Personal information & 53 & 14 \\
Employer in handle & 29 & N/A \\
Other news orgs & 15 & 1 \\
Disclaimer & 10 & 0 \\
Other journalists & 1 & 0 \\
\hline
\end{tabular}

Table 2. Bivariate correlations among branding and linking within tweets

\begin{tabular}{lccccc}
\hline & $\begin{array}{c}\text { Branding } \\
\text { of any kind }\end{array}$ & Individual & Organizational & Institutional & Link \\
\hline Individual & .043 & - & & & \\
Organizational & -.053 & $-.555^{* * *}$ & - & & \\
Institutional & $-.172^{* * *}$ & $-.294 * * *$ & $-.409^{* * *}$ & - & \\
Link & $.551^{* * *}$ & $.080^{* *}$ & $-.072^{*}$ & $.198^{* * *}$ & - \\
Public affairs & $.102^{* * *}$ & -.033 & .025 & $.121^{* * *}$ & $.137^{* * *}$ \\
\hline
\end{tabular}

Note: Cell entries are bivariate correlations (r). * $\mathrm{p}<.05 ; * * \mathrm{p}<.01 ; * * * \mathrm{p}<.001$. 